\title{
Research Publication of a selected University during 2011-2016: A Study Based on Scopus Database
}

\author{
Sankar, M \\ Tamil Nadu Agricultural University \\ Agricultural College \& Research Institute \\ Thiruvannamalai - 606753 \\ India
}

ABSTRACT: This Study explores the Research Output of Periyar University as reflected from the Scopus online database for the Period from 2011 to 2016. The Present paper investigates to find out the year wise output, topmost journals, most prolific authors, Documents and mostly occurred Keywords in the research. The study deals from the Scopus database and using MS Excel simple percentage analysis also been taken up to indentify the research output of Periyar University, Salem.

Keywords: Scopus, Scientometrics

Received: 18 August 2018, Revised 27 September 2018, Accepted 4 October 2018

DOI: $10.6025 / \mathrm{jitr} / 2019 / 10 / 1 / 12-16$

(C) 2019 DLINE. All Rights Reserved

\section{Introduction}

Periyar University is playing a paramount role in bringing multi-faceted development for the country. The University is consistently organising various academic activities to bring researchers, scholars, activists under one umbrella to discuss, deliberate and carve out time-demanding solutions to social problems. The funding agency of research has state, national, International, and various private agencies. The University is located on the National Highway (NH7) towards Bangalore at about $8 \mathrm{Kms}$ from New Bus Stand, Salem. It is well connected by frequent city bus services linking Salem and other places like, Omalur, Dharmapuri, Krishnagiri and Mettur. This paper discuss about the research output of Periyar University publication documents and frequently distribution of research output performances.

\section{Periyar University}

The Government of Tamil Nadu established the Periyar University at Salem on 17th September 1997 as per the provisions of the Periyar University Act, 1997. The University covers the area comprising the districts of Salem, Namakkal, Dharmapuri and Krishnagiri. The University got the 12 (B) and 2 f status from the University Grants Commission and has been reaccredited by NAAC with 'A' grade in 2015. The University is named after the Great Social Reformer E. V. Ramasamy affectionally called 'Thanthai Periyar'. The University aims at developing knowledge in various fields to realize the maxim inscribed in the logo 
"Arival Vilayum Ulagu" (Wisdom Maketh World). "Holistic development of the students" is the primary objective of the esteemed Periyar University. At present 8 Schools and divided into 27 Departments. The Government Arts \& Science Colleges 14, Constituents colleges 6, Government aided Colleges, Self Financing Colleges 77 and 1 University PG extension center are functioning under this university.

\section{Scopus Database}

Scopus is the largest abstract and citation database of peer-reviewed literature: scientific journals, books and conference proceedings. Delivering a comprehensive overview of the world's research output in the fields of science, technology, medicine, social sciences, and arts and humanities, Scopus features smart tools to track, analyze and visualize research.

\section{Scientometrics}

The term derived in the Wikipedia Scientometricsis the study of measuring and analysing science, technology and innovation. Major research issues include the measurement of impact, reference sets of articles to investigate the impact of journals and institutes, understanding of scientific citations, mapping scientific fields and the production of indicators for use in policy and management contexts. In practice there is a significant overlap between scientometrics and other scientific fields such as bibliometrics, information systems, information science and science of science policy. In 1969, Vassily V. Nalimov \& Z. M. Mulchenko coined the Russian equivalent of the term 'scientometrics' ('naukometriya') (Nalimov\&Mulchenko, 1969). As the name would imply, this term is mainly used for the study of all aspects of the literature of science and technology. The term had gained wide recognition by the foundation in 1978 of the Journal Scientometrics by Tibor Braun in Hungary all quantitative aspects of the science of science, communication in science.

\section{Review of Literature}

Raghuraman, Chanderand Madras (2010) describes the three-part study comparing the research performance of Indian institutions with that of other international institutions. In the first part, the publication profiles of various Indian institutions were examined and ranked based on the h-index and p-index. They found that the institutions of national importance contributed the highest in terms of publications and citations per institution. In the second part of the study, they looked at the publication profiles of various Indian institutions in the high-impact journals and compared these profiles against that of the top Asian and US universities. They found that the number of papers in these journals from India was miniscule compared to the US universities. Institutions do not compare favourably with the top US or Asian universities. Kademani et al., (2005) analysis of 1733 papers published by the teams comprising total of 926 participating scientists at Chemistry Division of Bhabha Atomic Research Centre (BARC) during 1970-1999 in the domains: Radiation \& Photochemistry and Chemical Dynamics (649), Solid State Studies (558), Inorganic, Structural and Materials Chemistry (460) and Theoretical Chemistry (66) were analysed for yearwise productivity, authorship pattern and collaboration. The highest number of publications in a year were 98 and 104 produced in 1989 and 1996 respectively. The average number of publications per year was 57.76. The highest collaboration coefficient 1.0 was in 1977 and 1999. Top ranking journals publishing chemistry division BARC publications were from UK (471), India (326), The Netherlands (302), USA (277) and Switzerland (104).

\section{Objectives of the Study}

- To identify the year wise distribution of research output of Periyar University.

- To identify the frequency of Top most Journal distribution in Periyar University. research output.

- To identify the frequency of Top most author distribution in Periyar University. research output.

- To identify the frequency of document type distribution in Periyar University. research out.

- To identify the frequency of Top most Keyword occured in Periyar University. 


\section{research output.}

\section{Methodology}

In this study the secondary sources are taken for analysis from the Scopus online database. The study period 2011 to 2016 take up as the database is available. The search string is ("Periyar University") secondary database scopus data was used to download the records based on the string. A total of 1824 records were downloaded for Periyar University Affiliation search and analyzed by using the MS Excel application as per the objectives of the study.

\section{Analysis}

\begin{tabular}{|l|l|l|l|}
\hline S. No & Publication Year & Record & \% \\
\hline 1 & 2016 & 328 & 17.98 \\
\hline 2 & 2015 & 361 & 19.79 \\
\hline 3 & 2014 & 348 & 19.08 \\
\hline 4 & 2013 & 281 & 15.41 \\
\hline 5 & 2012 & 292 & 16.01 \\
\hline 6 & 2011 & 214 & 11.73 \\
\hline & Total & $\mathbf{1 8 2 4}$ & $\mathbf{1 0 0}$ \\
\hline
\end{tabular}

Table 1. Showing frequency of Publication Year wise in Periyar University research output (Top 10)

There are variations in the number of publications of articles during the period taken for study. The accumulated percentage level indicates that the growth trend is gradually increased by recent years. Particularly, the (2014 and 2015) having good number of research publications. It could be derived from the above analysis; the years of 2015, 2014, 2016, 2012, 2013 and 2011 were having publications.

\begin{tabular}{|l|l|c|}
\hline Sl.No. & Journal Name & Nos \\
\hline 1. & Spectrochimica Acta Part A Molecular And Biomolecular Spectroscopy & 67 \\
\hline 2. & Acta Crystallographica Section E Structure Reports Online & 44 \\
\hline 3. & International Journal Of Pharmacy And Pharmaceutical Sciences & 41 \\
\hline 4. & International Journal Of Pharmaceutical Sciences Review And Research & 39 \\
\hline 5. & International Journal Of Applied Engineering Research & 38 \\
\hline 6. & International Journal Of Chemtech Research & 29 \\
\hline 7. & Indian Journal Of Science And Technology & 24 \\
\hline 8. & Journal Of Theoretical And Applied Information Technology & 24 \\
\hline 9. & International Journal Of Pharma And Bio Sciences & 23 \\
\hline 10. & Journal Of Chemical And Pharmaceutical Research & 21 \\
\hline
\end{tabular}

Table 2. Showing frequency of journal wise in Periyar University research output (Top 10)

14 Journal of Information Technology Review Volume 10 Number 1 February 2019


Out of 1824 journals, "Spectrochimica Acta Part a Molecular and Biomolecular Spectroscopy" has published the highest number of articles 67. Acta Crystallographica Section E Structure Reports Online 44 articles. It dominates in second place of research output in the Periyar University. The journal of "International Journal of Pharmacy and Pharmaceutical Sciences" has scored third place of articles published in the journal publications.

\begin{tabular}{|l|l|l|}
\hline Sl.No. & Name of Author & No. of Publications \\
\hline 1. & Kavitha, L. & 89 \\
\hline 2. & Gopi, D. & 84 \\
\hline 3. & Thangavel, K. & 63 \\
\hline 4. & Chandrasekar, C. & 59 \\
\hline 5. & Krishnakumar, V. & 50 \\
\hline 6. & Murugavel, S. & 48 \\
\hline 7. & Krishnaveni, M. & 47 \\
\hline 8. & Viswanathamurthi, P. & 47 \\
\hline 9. & Venkatachalam, P. & 46 \\
\hline 10. & Anbarasan, P.M. & 44 \\
\hline
\end{tabular}

Table 3. Showing frequency of Author wise in Periyar University research output (Top 10)

Dr. Kavitha, L. Assistant professor in Physics at Periyar University Published 89 documents. Dr. Gopi, D., Professor of Chemistry, Periyar University got second position 84 documents and third Position Dr. Thangavel, K. Professor \& Head, Department of Computer at Periyar University, published 63 documents. Most of the physical Science oriented scientist predominant role played in the top ten research ouput level of Periyar University.

\begin{tabular}{|l|l|l|l|}
\hline No. & Document Type & No. of Documents & Percentage \\
\hline 1 & Article & 1554 & 85.2 \\
\hline 2 & Conference Paper & 189 & 10.4 \\
\hline 3 & Book Chapter & 31 & 1.7 \\
\hline 4 & Review & 29 & 1.6 \\
\hline 5 & Book & 6 & 0.3 \\
\hline 6 & Editorial & 6 & 0.3 \\
\hline 7 & Article in Press & 5 & 0.3 \\
\hline 8 & Erratum & 2 & 0.1 \\
\hline 9 & Letter & 2 & 0.1 \\
\hline & Total & $\mathbf{1 8 2 4}$ & $\mathbf{1 0 0}$ \\
\hline
\end{tabular}

Table 4. Showing frequency of document wise in Periyar University research output 
Periyar University Scientists communicated their research results through a variety of communication channels. The above table and figure provides the distribution of publications in various forms of information. It was observed that 85.2 percent of the literature was published in Article followed by 10.4 percent in conference paper, 1.7 percent in Book chapter, 1.6 in Review, 0.3 percent Book, Editorial and Article in Press. An Erratum and Letter documents are 0.1 percent.

\begin{tabular}{|l|l|l|}
\hline S. No & Keyword & Record \\
\hline 1 & Article & 542 \\
\hline 2 & Nonhuman & 313 \\
\hline 3 & Controlled Study & 253 \\
\hline 4 & Unclassified Drug & 224 \\
\hline 5 & Chemistry & 166 \\
\hline 6 & X Ray Diffraction & 164 \\
\hline 7 & Infrared Spectroscopy & 149 \\
\hline 8 & Plant Extract & 140 \\
\hline 9 & Scanning Electron Microscopy & 126 \\
\hline 10 & Human & 119 \\
\hline
\end{tabular}

Table 5. Showing frequency of Keyword in Periyar University research output (Top 10)

Periyar University word has occurred from the Article at 542 times, Nonhuman 313, Controlled Study 253, Unclassified Drug 224, Chemistry 166, X Ray Diffraction 164, Infrared Spectroscopy 149, Plant Extract 140, Scanning Electron Microscopy 126, and Human 119 words are have been occurred from the research publication of Periyar university period of 2011-2016.

\section{Conclusion}

The research productivity of Periyar university exhibits a gradual growth during the study period. It could be derived from the above analysis; the years of 2015, 2014, 2016, 2012, 2013 and 2011 were having publications. "Spectrochimica Acta Part a Molecular and Biomolecular Spectroscopy" has published the highest number of articles for the period 2011-2016. The Top most author is Dr. Kavitha, L. Assistant professor in Physics at Periyar University Published 89 documents. It is contingent that the leading source is the form of journal articles compared to the other documents.

\section{References}

[1] Kademani, B. S. (2005). Scientometric dimensions of innovation communication productivity of the chemistry division at Bhabha Atomic Research Centre, Malaysian Journal of Library and Information Science 10 (1) 65-89.

[2] Nalimov, Vassily, V., Mulchenko. (1969). Naukometriya. Izuchenie Razvitiya Naukikak Informatsionnogo Protsessa. [Scientometrics. Study of the Development of Science as an Information Process], Nauka, Moscow, (English translation: 1971. Washington, D.C.: Foreign Technology Division. U.S. Air Force Systems Command, Wright-Patterson AFB, Ohio. (NTIS Report No.AD735-634)(1969b).

[3] Raghuraman, K. P., Chander, R., Madras, G. (2010). Scientometric analysis of some disciplines: Comparison of Indian institutions with other international institutions, Current Science 99 (5) 577-587.

[4] https://www.scopus.com/(Accessed 22 February 2018)

[5] http://www.periyaruniversity.ac.in(Accessed 22 February 2018)

\begin{tabular}{lllllll}
\hline 16 & Journal of Information Technology Review & Volume & 10 & Number & 1 & February \\
\hline
\end{tabular}

